\title{
Article \\ The Essential-Oil-Bearing Rose Collection Variability Study in Terms of Biochemical Parameters
}

\author{
Viktor Zolotilov ${ }^{1}$, Natalya Nevkrytaya ${ }^{1, *(\mathbb{D},}$, Olga Zolotilova $^{1}$, Sevilia Seitadzhieva ${ }^{1}\left(\mathbb{D}\right.$, Elena Myagkikh ${ }^{1}(\mathbb{D}$, \\ Vladimir Pashtetskiy ${ }^{1}$ and Mikhail Karpukhin ${ }^{2}$
}

check for updates

Citation: Zolotilov, V.; Nevkrytaya, N.; Zolotilova, O.; Seitadzhieva, S.;

Myagkikh, E.; Pashtetskiy, V.;

Karpukhin, M. The

Essential-Oil-Bearing Rose Collection

Variability Study in Terms of

Biochemical Parameters. Agronomy

2022, 12, 529. https://doi.org/

10.3390/agronomy12020529

Academic Editors: Andrey

Georgievich Koshchaev, Irina

M. Donnik, Viktor

Stanislavovich Kukhar and

Dzintra Dēkena

Received: 2 February 2022

Accepted: 19 February 2022

Published: 20 February 2022

Publisher's Note: MDPI stays neutral with regard to jurisdictional claims in published maps and institutional affiliations.

Copyright: (C) 2022 by the authors. Licensee MDPI, Basel, Switzerland. This article is an open access article distributed under the terms and conditions of the Creative Commons Attribution (CC BY) license (https:// creativecommons.org/licenses/by/ $4.0 /)$.
1 Research Institute of Agriculture of Crimea, Kievskaya St., 150, 295453 Simferopol, Russia; viktor_zolotilov@mail.ru (V.Z.); olya_zolotilova@mail.ru (O.Z.); cepen@mail.ru (S.S.); myagkih_e@niishk.ru (E.M.); pvs98a@gmail.com (V.P.)

2 Faculty of Biotechnology and Food Engineering, Ural State Agrarian University, Karla Liebknechta St., 42, 620075 Yekaterinburg, Russia; mkarpukhin@yandex.ru

* Correspondence: nevkritaya@mail.ru; Tel.: +7-978-8307553

\begin{abstract}
The primary task when breeding new varieties of essential-oil-bearing rose is to increase the essential oil content and quality. The purpose of the present research is to study the essential-oilbearing rose collection variability in terms of the essential oil content and component composition and to identify opportunities for isolating the specimens promising for selection. The study of a collection of 112 specimens was carried out in 2017-2020 in the context of the piedmont of Crimea. The decanted essential oil content was determined using the hydrodistillation method. The component composition of rose essential oil was analyzed by gas chromatography on Crystal 5000.2. The essential oil components were identified by comparing their Kovats retention indices to the literature values. A high variability in the essential oil content in the collection $(\mathrm{Cv}=36.3 \%$ at the average, over 4 years) and the major components content in the essential oil ( $\mathrm{Cv}=22.1-45.9 \%)$ was found. In the context of the piedmont of Crimea, the major components' percentage content in essential oil from all the specimens including the five Bulgarian varieties did not meet the GOST ISO 9842 2017 standard requirements. This is indicative of a high-degree sensitivity to the soil and weather conditions in the region. It was found that the citronellol, geraniol, and nerol content in essential oil dropped significantly in extreme high temperature and drought conditions. Seven specimens rich in essential oil contained in the raw plant material $(0.030-0.049 \%)$ and thirteen specimens with a high yield of concrete $(0.31-0.39 \%)$ were identified and have been recommended for inclusion in the breeding process.
\end{abstract}

Keywords: oil-bearing rose; essential oil; chemical composition; citronellol; geraniol; nerol; concrete

\section{Introduction}

Essential-oil-bearing rose is one of the best known and precious essential-oil-bearing plants. The plant is highly valued due to essential oil accumulated in the plant flower heads. The essential oil content in the rose flower head is as low as $0.03-0.05 \%$. Subject to further use, the rose flowers are processed using hydro distillation and extraction methods. The derived products include distillated (decanted) or extraction oil, concrete, absolute, hydrolate, and wax [1,2].

Rose essential oil is one of the most expensive and least toxic oils. It has a complex component composition and contains constituents such as geraniol, nerol, citronellol, farnesol, linalool, limonene, 1-p-menthene, myrcene, and pinene, at different ratios [1-4]. Biologically active substances, including tannins, organic acids, beta carotene, cyanine, resins, and wax, are of great value as well. The rose flower head derivatives are the highest priority for rose essential oil, due to the high value of their component composition, and are used widely in the perfume and toiletry industry, pharmaceutical production, medicine, and aromatherapy [2,5-8]. 
Rose oil exhibits antiseptic, spasmolytic, antiviral, antibacterial, antifungal, diuretic, aphrodisiac, cicatrizing, cleansing, stimulating, and sedative properties [6,7].

It is found that rose essential oil exhibits an inhibitory activity against the tested Gram-positive and Gram-negative microorganisms. There is evidence indicative of its antiradical and metal chelating activity and its ability to inhibit lipid peroxidation [8].

Essential oil from the Bulgarian Kazanlak rose is the most in-demand for use in the perfume and toiletry industry. Essential oil from the Crimean varieties, formerly widely used in domestic production, does not meet the requirements of the world perfumery formulae. Presently, the State Register of Selection Achievements Authorized for Use of Russia includes five varieties-Raduga, Lan, Lada, Legrina, and Zolushka-originated and owned by the Research Institute of Agriculture of Crimea (RIAC) [9]. Because the essential oil extracted from their flower heads is inferior in quality to essential oil from the Kazanlak rose, breeding and developing varieties adequately competing with the Kazanlak rose remains a challenging task. Improving the quality of essential oil from domestic varieties is particularly topical in the context of the strides currently being made toward a large-scale rehabilitation of essential oil production in Russia, and replacing the plant raw material derivative products imports by domestically produced substitutes. Therefore, in the context of breeding studies, the Kazanlak rose is one of the main components of hybridization. Promising breeding materials to be developed alongside the Kazanlak rose as well as other specimens from the collection material should be included into the breeding process.

The essential-oil-bearing plants breeding and seed centre under RIAC maintains, replenishes, and studies the collection of essential-oil-bearing roses as part of the gene pool collection of spicy, aromatic, essential-oil-bearing, and medicinal plants registered in Russia as a unique scientific facility (USF no. 507515 (http / / www.ckp-rf.ru, accessed on 19 December 2021).

The purpose of the present research is to study the essential-oil-bearing rose collection variability in terms of the essential oil content and component composition, and to identify opportunities for isolating the specimens promising for selection.

\section{Materials and Methods}

The study of the essential-oil-bearing rose collection was carried out in 2017-2020 at the experimental site of the essential-oil-bearing and medicinal plants department of the RIAC located in the piedmont of Crimea (Krymskaya Roza village, Belogorsky district). The local climate is moderately continental. The area falls under one of the five agroclimatic zones-the upper piedmont, warm and sub-humid, and the northern subzone with a moderately mild winter [5]. The average annual air temperature is $10{ }^{\circ} \mathrm{C}$. The duration of the positive air temperature period is 292 days a year. The average temperature in the warmest month of the year, July, is $21^{\circ} \mathrm{C}$, and for the coldest month of the year, January, it is $-0.8{ }^{\circ} \mathrm{C}$. The highest possible temperature in summer is $40^{\circ} \mathrm{C}$ and the lowest possible temperature in winter is $-30-35^{\circ} \mathrm{C}$. The long-term average precipitation amount is $498 \mathrm{~mm}$, and during the vegetation period it is $280 \mathrm{~mm}$. The average annual air humidity is $70 \%$, and the Selyaninov Hydrothermal Coefficient (HTC) is 0.91, which is evidence of an arid climate. The soil at the experimental site is southern carbonated, heavy loamy chernozem (pH 7.0-8.0).

The collection comprises 50 specimens: 20 varieties, including 5 varieties owned by RIAC, 5 varieties from Bulgaria (Kazanlak, Svezhen, Belaya, Iskra, and Vesna), and selection specimens and hybrids originating from Ukraine, Russia, and Moldova.

The essential-oil-bearing rose collection nursery was laid in 2010-2012. The collection specimens are placed at single-row working plots, with 5-10 plants per row. The planting pattern is $2.50 \times 1.0 \mathrm{~m}$. The decanted essential oil content in each specimen was evaluated in three stages - at the start of harvesting, in the middle, and at the end of harvesting. Analysis was carried out by hydrodistillation using Ginzberg's device, in accordance with the developed techniques and standard requirements of GOST 34213-2017 [10-12]. The 
weight of a sample (flowers) was $500 \mathrm{~g}$, and the oil extraction time was $2 \mathrm{~h}$ from the start of distillation.

The component composition of the decanted rose oil was analyzed by gas chromatography on the Crystal 5000.2 chromatograph with a flame ionization detector [13]. For the major components of essential oil to be identified and isolated, the following chromatographic conditions were selected: a 30-m long fused silica column, $0.32 \mathrm{~mm}$ in internal diameter, and 0.5-micron thick film. The stationary phase was CR-WAXms. The column heating oven temperature program was set as follows: $1-\mathrm{min}$ exposure at $75{ }^{\circ} \mathrm{C}$, then $4{ }^{\circ} \mathrm{C} / \mathrm{min}$ to $220^{\circ} \mathrm{C}$ for $5 \mathrm{~min}$. The injector and detector temperature were $230{ }^{\circ} \mathrm{C}$ and 250 ${ }^{\circ} \mathrm{C}$, respectively. The carrier gas flow was $1 \mathrm{~mL} / \mathrm{min}$, and the carrier gas split ratio was $1 / 20$. Helium was used as a carrier gas. The total chromatography time was 42.3 min.

The essential oil components were identified by comparing their Kovats retention indices to the literature values. The Kovats retention indices were determined relative to the homologous n-alkanes series (C8-C40) in the same operational conditions. The components were further identified by comparing the essential oil chromatographic profile (the fingerprint identification method) upon the specimens' preliminary analysis on the Agilent Technologies $6890 \mathrm{~N}$ mass spectrometer with the Agilent $5973 \mathrm{~N}$ mass selective detector and on the Crystal 5000.2 chromatograph in similar chromatographic conditions (Chromatec, Yoshkar-Ola, Mari-El, Russian Federation) [14].

All of the analyses were performed in triplicate.

Statistical processing of the data obtained was carried out using the Microsoft Office Excel 2010 software package [15]. The mean values and the error of mean $(\bar{X} \pm S \bar{x})$ were calculated for each specimen annually.

\section{Results and Discussion}

The weather conditions varied through the study years (Figure 1). This let us to make a clear-eyed assessment of the study specimens in terms of the test parameter manifestation pattern and adaptability to changing weather conditions. The year 2017 was the most favorable in terms of the temperature-humidity conditions. A significant rise in the average many-year temperature (normal) was registered in March $\left(+4{ }^{\circ} \mathrm{C}\right.$ higher than normal). In April and May, the temperature conditions were at the level of the average many-year temperature. Precipitation was less in March (64.9\% lower than normal) and significantly more in April and May (86.2 and 51.9\% higher than normal, respectively).

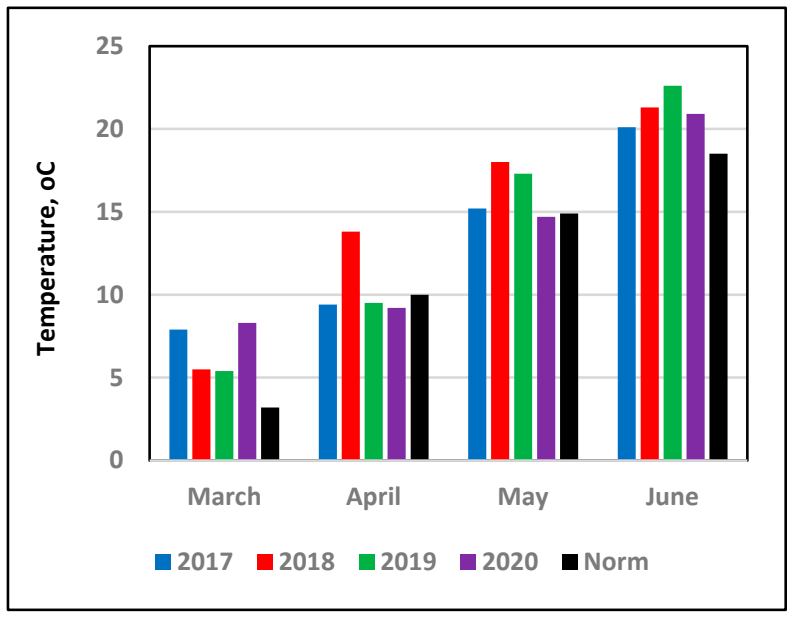

(A)

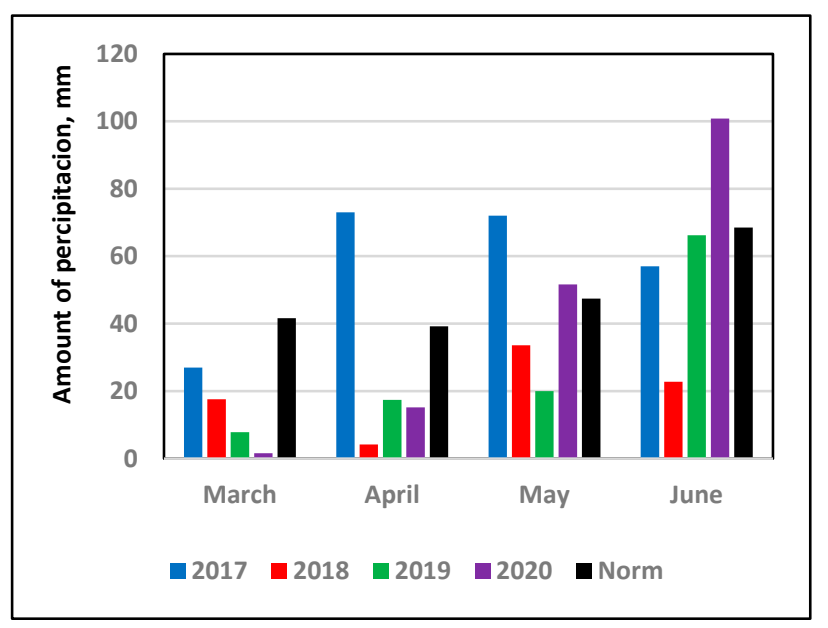

(B)

Figure 1. (A) Average monthly air temperature during the period of active vegetation, 2017-2020, and (B) average monthly precipitation during the period of active vegetation, 2017-2020.

The following year, 2018, was extremely hot and dry. Through all the months, except for March, the temperature was significantly higher than the mean values. March-May 
were extremely dry. In April, precipitation was as little as 10.7\% of the normal amount. Only in mid-May, did $30 \mathrm{~mm}$ precipitation fell within one day.

In terms of weather conditions, 2019 fell in between 2017 and 2018. Spring was dry; precipitation in April and May was 44.2 and $42.2 \%$ of the normal amount, respectively; and heavy precipitation fell out in the second half of June upon completion of the rose blooming period. In April and May, the temperature conditions were higher than normal, but lower than in 2018.

In 2020, a significant rise in the average air temperature $\left(+5.1^{\circ} \mathrm{C}\right.$ higher $)$ was registered in March. During the rest of the active vegetation period, the temperature was close to the mean values. March and April were extremely dry (precipitation was 3.8 and $38.8 \%$ of the normal amount). Precipitation in May was at the normal level, and in June it was $47.2 \%$ more than normal.

The essential oil content was the highest in the flowers harvested in the early morning. However, in cold, rainy, or cloudy weather, the essential oil content was higher in the flowers harvested at a later time [16]. This factor was considered when carrying out the study. Based on the findings of a biochemical analysis of the essential-oil-bearing rose collection, the essential oil content in the collection specimens' raw material within the period of $2017-2020$ averaged $0.023 \pm 0.001 \%$ at the range of variation from 0.005 to $0.057 \%$ (Table 1).

Table 1. Characteristics of the essential-oil-bearing rose collection in terms of the essential oil content and the major components ratio, 2017-2020.

\begin{tabular}{|c|c|c|c|c|c|}
\hline \multirow{2}{*}{ Indicator Value } & \multirow{2}{*}{ Year } & \multirow{2}{*}{$\begin{array}{c}\text { Mass Fraction of } \\
\text { Essential Oil, \% }\end{array}$} & \multicolumn{3}{|c|}{ Major Components Content, \% } \\
\hline & & & Citronellol & Nerol & Geraniol \\
\hline \multirow{5}{*}{ Mean value in the collection } & 2017 & $0.024 \pm 0.002$ & - & - & - \\
\hline & 2018 & $0.025 \pm 0.002$ & $8.31 \pm 0.88$ & $7.74 \pm 0.70$ & $32.54 \pm 1.73$ \\
\hline & 2019 & $0.022 \pm 0.001$ & $8.90 \pm 0.90$ & $10.37 \pm 0.84$ & $37.82 \pm 2.04$ \\
\hline & 2020 & $0.019 \pm 0.001$ & $11.11 \pm 1.18$ & $10.13 \pm 0.95$ & $33.02 \pm 2.04$ \\
\hline & $\bar{X} \pm S \bar{x}$ & $0.023 \pm 0.001$ & $9.69 \pm 0.67$ & $9.41 \pm 0.49$ & $34.60 \pm 1.15$ \\
\hline \multirow{5}{*}{ Indicator range } & 2017 & $0.005-0.053$ & - & - & - \\
\hline & 2018 & $0.005-0.057$ & $1.9-17.8$ & $2.0-17.2$ & $13.2-44.4$ \\
\hline & 2019 & $0.008-0.048$ & $3.4-17.5$ & $1.8-17.2$ & $12.7-51.3$ \\
\hline & 2020 & $0.009-0.037$ & $3.8-25.5$ & $1.6-20.5$ & $7.5-47.2$ \\
\hline & $\bar{X} \pm S \bar{x}$ & $0.007-0.049$ & $3.80-20.27$ & $3.86-18.28$ & $15.78-4.55$ \\
\hline \multirow{5}{*}{ Coefficient of variation $(\mathrm{Cv}), \%$} & 2017 & 37.5 & - & - & - \\
\hline & 2018 & 37.5 & 52.3 & 46.7 & 26.0 \\
\hline & 2019 & 36.4 & 49.2 & 39,5 & 26.4 \\
\hline & 2020 & 47.4 & 51.9 & 46.0 & 30.3 \\
\hline & $\bar{X} \pm S \bar{x}$ & 36.6 & 45.9 & 34.5 & 22.1 \\
\hline
\end{tabular}

The highest essential oil content in flowers, $0.030-0.049 \%$, was identified in seven specimens-Festivalnaya, M340, Kooperatorka, G142, A4622, 375, and Aura (RIAC). The essential oil content was the highest in the Aura variety $(0.049 \pm 0.004 \%)$ and the lowest in the G1389 specimen $(0.005 \pm 0.000 \%)$. The essential oil content in the Raduga, Lan, Lada, and Legrina varieties was the same- $-0.025-0.026 \%$. The above-average variability in the essential oil content $(\mathrm{Cv}=36.3 \%)$ points to the possibility to select promising specimens in view of this indicator for breeding varieties rich in essential oil.

The rose essential oil quality depends on its component composition and, most particularly, the terpene alcohols-citronellol, nerol and geraniol-ratio. The reference standard for selection is the component composition of the so-called "Bulgarian rose essential oil" extracted from the Kazanlak rose using the hydrodistillation method. According to the data provided by researchers from the rose oil producer countries, the major components 
content in the Bulgarian rose essential oil is as follows: citronellol 20-38\%, geraniol 14-20\%, and nerol 7-13\% [3].

As per the interstate standard (GOST ISO 9842-2017 ESSENTIAL OIL OF ROSE (Rosa damascena Miller)) specifications, the major components ratio is as shown in Table 2 [17].

Table 2. GOST ISO 9842-2017 standard requirements for the rose essential oil major component contents for multiple countries.

\begin{tabular}{|c|c|c|c|c|c|c|c|c|}
\hline \multirow[b]{2}{*}{ Component } & \multicolumn{2}{|c|}{ Bulgaria } & \multicolumn{2}{|c|}{ Turkey } & \multicolumn{2}{|c|}{ Morocco } & \multicolumn{2}{|c|}{ Turkey ("Rural" Type) } \\
\hline & $\underset{\%}{\text { Minimum, }}$ & $\begin{array}{c}\text { Maximum, } \\
\%\end{array}$ & $\underset{\%}{\text { Minimum, }}$ & $\underset{\%}{\text { Maximum, }}$ & $\underset{\%}{\text { Minimum, }}$ & $\begin{array}{c}\text { Maximum, } \\
\%\end{array}$ & $\underset{\%}{\text { Minimum, }}$ & $\underset{\%}{\text { Maximum, }}$ \\
\hline Ethanol & - & 2.0 & - & 7 & - & 3 & - & 2.0 \\
\hline Citronellol & 20.0 & 34.0 & 34.0 & 49.0 & 30.0 & 47.0 & 26 & 40.0 \\
\hline Nerol & 5.0 & 12.0 & 3.0 & 11.0 & 3.0 & 11.0 & 6.0 & 12.0 \\
\hline Geraniol & 15.0 & 22.0 & 8.0 & 20.0 & 6.0 & 23.0 & 12.0 & 29.0 \\
\hline B-phenyleta-nol & - & 3.5 & - & 3.0 & - & 3.0 & - & 3.0 \\
\hline $\begin{array}{l}\text { Heptadecane } \\
\text { (paraffin C17) }\end{array}$ & 1.0 & 2.5 & 0.8 & 3.0 & 0.6 & 4.0 & 0.7 & 3.0 \\
\hline $\begin{array}{l}\text { Nonadecane } \\
\text { (paraffin C19) }\end{array}$ & 8.0 & 15.0 & 6.0 & 13.0 & 7.0 & 16.0 & 6.0 & 8.5 \\
\hline $\begin{array}{l}\text { Heneicosane } \\
\text { (paraffin C21) }\end{array}$ & 3.0 & 5.5 & 2.0 & 4.0 & 2.0 & 5.5 & 1.5 & 4.0 \\
\hline
\end{tabular}

Minor components affect essential oil odor, and thus do not play an important part. Minor components include, primarily, rose oxide, beta-damascenone, beta-ionone, and beta-damascone. However, their amounts are not regulated by the standard requirements of GOST ISO 9842-2017 [2].

As seen from the parameters approved by the relevant regulatory documents (Table 2), the major components standard ratio in essential oil from roses cultivated and processed in multiple countries varies wildly.

The component composition of essential oils from 44 specimens was analyzed within the context of the essential-oil-bearing rose collection study. The component composition of essential oil from six specimens was not analyzed due to the scarcity of the raw material.

On average, in 2017-2020, the essential oil major components content in the collection specimens was as follows: citronellol $9.69 \pm 0.67 \%$, variation range $3.80-20.27 \%$, geraniol $34.60 \pm 1.15 \%$ (15.78-46.55\%), and nerol $9.41 \pm 0.49 \%$ (3.86-18.28\%; Table 1$)$. The total stearoptenes had an average rate of $20.0 \pm 1.1 \%$ and variation range of $6.8-37.2 \%$.

High variability in the major components content $(\mathrm{Cv}=22.1-45.9 \%)$ makes for figuring opportunities for developing a promising breeding material with the major components ratio close to the GOST ISO 9842-2017 standard requirements.

For comparison, the rose essential oil major components ratio in five Bulgarian specimens and five varieties owned by RIAC included in the study collection is given in Table 3.

The chromatographic analysis findings testify that none of the Bulgarian specimens, including the Kazanlak rose cultivated in the context of Crimea, met the standard requirements of GOST ISO 9842-2017 in terms of the major components ratio in essential oils (Tables 2 and 3). This is proof that the component composition of the rose essential oil, as surely as the component composition of essential oil of other essential-oil-bearing plants, is highly sensitive to processing technologies and a range of other factors including soil and climatic conditions in the plant growing region [2-5,18]. For example, when examining the component composition of essential oil from Melissa officinalis L. Krymchanka and Lada varieties cultivated in the piedmont of Crimea, Moscow region (Central nonchernozem belt, Russia) and in the Krasnodar Krai (Western Pre-Caucasian region), we revealed significant differences in the essential oil components ratio subject to the climatic pattern of the region and weather conditions during the study years [19]. Significant variability in the rose essential oil component composition subject to the cultivation region was identified when analyzing the plant populations from 15 regions in Kashan (Iran). The citronellol content was volatile between 16.2 and $57.8 \%$, and that of geraniol varied from 0.9 to $14.1 \%$ [20]. The 
study of essential oil from the rose cultivated in the south of Iran showed that its major components were nonadecane $(39.73 \%)$ and heneicosane $(32.38 \%)$, while the citronellol content was as little as $6.14 \%$ [21].

Table 3. The essential oil major component percentages in the collection specimens from Bulgaria and RIAC, 2018-2020.

\begin{tabular}{|c|c|c|c|c|c|c|}
\hline \multirow{2}{*}{ Specimen } & \multirow{2}{*}{ Year } & \multirow{2}{*}{$\begin{array}{l}\text { Mass Fraction of } \\
\text { Essential Oil, \% }\end{array}$} & \multicolumn{4}{|c|}{ Major Components Content, \% } \\
\hline & & & Citronellol & Nerol & Geraniol & Stearoptenes \\
\hline \multicolumn{7}{|c|}{ Bulgarian selection varieties } \\
\hline \multirow{4}{*}{ R-17 Kazanlak } & 2018 & $0.027 \pm 0.001$ & $12.9 \pm 0.3$ & $5.9 \pm 0.2$ & $24.8 \pm 1.1$ & $28.0 \pm 0.7$ \\
\hline & 2019 & $0.025 \pm 0.002$ & $13.3 \pm 0.2$ & $9.0 \pm 0.1$ & $31.2 \pm 0.6$ & $22.1 \pm 2.4$ \\
\hline & 2020 & $0.012 \pm 0.001$ & $13.7 \pm 0.5$ & $7.3 \pm 0.4$ & $28.1 \pm 0.3$ & $17.8 \pm 1.3$ \\
\hline & $\bar{X} \pm S \bar{x}$ & $0.021 \pm 0.005$ & $13.3 \pm 0.2$ & $7.4 \pm 0.9$ & $28.0 \pm 1.8$ & $22.6 \pm 3.0$ \\
\hline \multirow{4}{*}{$\mathrm{R}-18$ Iskra } & 2018 & $0.024 \pm 0.001$ & $12.5 \pm 0.6$ & $6.7 \pm 0.2$ & $24.2 \pm 1.0$ & $27.3 \pm 1.5$ \\
\hline & 2019 & $0.028 \pm 0.001$ & $14.0 \pm 1.1$ & $9.7 \pm 0.0$ & $35.2 \pm 1.9$ & $15.9 \pm 0.3$ \\
\hline & 2020 & $0.019 \pm 0.002$ & $16.1 \pm 0.4$ & $8.6 \pm 0.2$ & $31.3 \pm 1.2$ & $20.9 \pm 0.9$ \\
\hline & $\bar{X} \pm S \bar{x}$ & $0.024 \pm 0.002$ & $14.2 \pm 1.04$ & $8.3 \pm 0.9$ & $30.2 \pm 3.2$ & $21.4 \pm 3.9$ \\
\hline \multirow{4}{*}{ R-32 Vesna } & 2018 & $0.024 \pm 0.001$ & $6.0 \pm 0.2$ & $9.8 \pm 0.1$ & $38.7 \pm 0.7$ & $21.5 \pm 3.8$ \\
\hline & 2019 & $0.025 \pm 0.002$ & $6.2 \pm 0.5$ & $12.8 \pm 0.3$ & $41.7 \pm 1.3$ & $17.6 \pm 2.4$ \\
\hline & 2020 & $0.021 \pm 0.001$ & $5.8 \pm 0.3$ & $11.2 \pm 0.4$ & $39.0 \pm 1.8$ & $18.4 \pm 1.2$ \\
\hline & $\bar{X} \pm S \bar{x}$ & $0.023 \pm 0.002$ & $6.0 \pm 0.2$ & $11.3 \pm 1.0$ & $39.9 \pm 0.9$ & $19.1 \pm 1.2$ \\
\hline \multirow{4}{*}{ R-4 Svezhen } & 2018 & $0.029 \pm 0.002$ & $17.8 \pm 0.6$ & $7.7 \pm 0.4$ & $29.3 \pm 1.2$ & $16.0 \pm 3.1$ \\
\hline & 2019 & $0.025 \pm 0.001$ & $12.7 \pm 1.3$ & $9.3 \pm 0.7$ & $32.9 \pm 3.8$ & $21.5 \pm 6.4$ \\
\hline & 2020 & $0.025 \pm 0.002$ & $24.8 \pm 0.9$ & $9.8 \pm 0.3$ & $30.0 \pm 2.7$ & $14.2 \pm 2.4$ \\
\hline & $\bar{X} \pm S \bar{x}$ & $0.026 \pm 0.001$ & $18.4 \pm 3.5$ & $8.9 \pm 0.6$ & $30.7 \pm 1.1$ & $17.2 \pm 1.9$ \\
\hline \multirow{4}{*}{$\begin{array}{c}\text { R-33 Kazanlak } \\
\text { White }\end{array}$} & 2018 & $0.021 \pm 0.001$ & $7.0 \pm 0.7$ & $7.1 \pm 0.6$ & $38.5 \pm 1.9$ & $16.6 \pm 2.7$ \\
\hline & 2019 & $0.020 \pm 0.002$ & $6.8 \pm 1.1$ & $10.4 \pm 1.8$ & $42.2 \pm 3.1$ & $17.8 \pm 4.9$ \\
\hline & 2020 & $0.015 \pm 0.001$ & $8.6 \pm 0.3$ & $8.1 \pm 0.1$ & $40.6 \pm 4.0$ & $21.5 \pm 3.1$ \\
\hline & $\bar{X} \pm S \bar{x}$ & $0.019 \pm 0.002$ & $7.5 \pm 0.5$ & $8.5 \pm 1.0$ & $40.4 \pm 1.1$ & $18.6 \pm 1.4$ \\
\hline \multicolumn{7}{|c|}{ RIAC-owned varieties } \\
\hline \multirow{4}{*}{ R-7 Raduga } & 2018 & $0.023 \pm 0.001$ & $4.9 \pm 0.7$ & $2.0 \pm 0.2$ & $17.3 \pm 0.7$ & $36.0 \pm 4.3$ \\
\hline & 2019 & $0.019 \pm 0.002$ & $3.1 \pm 0.1$ & $7.7 \pm 0.2$ & $45.4 \pm 0.1$ & $18.9 \pm 2.3$ \\
\hline & 2020 & $0.033 \pm 0.001$ & $7.2 \pm 0.1$ & $6.7 \pm 0.4$ & $40.7 \pm 1.2$ & $15.8 \pm 5.2$ \\
\hline & $\bar{X} \pm S \bar{x}$ & $0.025 \pm 0.003$ & $5.0 \pm 1.2$ & $5.5 \pm 1.8$ & $34.4 \pm 8.7$ & $23.5 \pm 6.3$ \\
\hline \multirow{4}{*}{ R-13 Lan } & 2018 & $0.024 \pm 0.001$ & $8.9 \pm 0.3$ & $8.9 \pm 0.7$ & $37.2 \pm 2.1$ & $6.1 \pm 1.1$ \\
\hline & 2019 & $0.025 \pm 0.001$ & $12.3 \pm 0.2$ & $17.2 \pm 0.6$ & $48.1 \pm 0.6$ & $13.3 \pm 2.2$ \\
\hline & 2020 & $0.025 \pm 0.001$ & $10.3 \pm 0.5$ & $11.8 \pm 1.1$ & $42.9 \pm 1.8$ & $11.7 \pm 5.3$ \\
\hline & $\bar{X} \pm S \bar{x}$ & $0.025 \pm 0.000$ & $10.5 \pm 1.0$ & $12.6 \pm 2.4$ & $42.7 \pm 3.1$ & $10.3 \pm 2.2$ \\
\hline \multirow{4}{*}{ R-14 Lada } & 2018 & $0.028 \pm 0.001$ & $8.4 \pm 0.2$ & $9.6 \pm 0.4$ & $43.3 \pm 1.3$ & $15.3 \pm 3.2$ \\
\hline & 2019 & $0.025 \pm 0.002$ & $5.4 \pm 0.1$ & $13.2 \pm 0.2$ & $41.8 \pm 2.3$ & $11.2 \pm 2.3$ \\
\hline & 2020 & $0.025 \pm 0.001$ & $5.9 \pm 0.4$ & $12.4 \pm 0.7$ & $43.4 \pm 0.6$ & $13.8 \pm 8.1$ \\
\hline & $\bar{X} \pm S \bar{x}$ & $0.026 \pm 0.001$ & $6.6 \pm 0.9$ & $11.7 \pm 1.1$ & $42.8 \pm 0.5$ & $13.4 \pm 1.2$ \\
\hline \multirow{4}{*}{ R-12 Legrina } & 2018 & $0.027 \pm 0.002$ & $10.7 \pm 0.7$ & $11.2 \pm 0.9$ & $33.5 \pm 0.9$ & $7.6 \pm 3.1$ \\
\hline & 2019 & $0.025 \pm 0.002$ & $12.2 \pm 0.9$ & $12.5 \pm 0.3$ & $36.5 \pm 1.1$ & $16.4 \pm 2.5$ \\
\hline & 2020 & $0.024 \pm 0.001$ & $10.5 \pm 0.2$ & $13.3 \pm 1.6$ & $33.8 \pm 1.7$ & $18.5 \pm 4.3$ \\
\hline & $\bar{X} \pm S \bar{x}$ & $0.026 \pm 0.001$ & $11.2 \pm 0.5$ & $12.3 \pm 0.6$ & $34.6 \pm 1.0$ & $14.0 \pm 3.2$ \\
\hline \multirow{4}{*}{ R-20 Zolushka } & 2018 & $0.005 \pm 0.001$ & $7.8 \pm 0.9$ & $1.8 \pm 0.3$ & $12.7 \pm 2.1$ & $29.5 \pm 3.7$ \\
\hline & 2019 & $0.009 \pm 0.001$ & $3.4 \pm 0.2$ & $5.1 \pm 0.5$ & $28.1 \pm 3.2$ & $39.5 \pm 4.1$ \\
\hline & 2020 & $0.011 \pm 0.001$ & $10.3 \pm 0.7$ & $4.8 \pm 0.1$ & $23.0 \pm 0.8$ & $29.8 \pm 5.6$ \\
\hline & $\bar{X} \pm S \bar{x}$ & $0.008 \pm 0.002$ & $7.2 \pm 2.0$ & $3.9 \pm 1.0$ & $21.2 \pm 4.5$ & $32.9 \pm 3.3$ \\
\hline
\end{tabular}

The rose essential oil major components' ratio sensitivity to weather conditions was identified by comparing the major component contents in 24 specimens using the chromatographic analysis, which was done over 3 years (2018-2020). 
The highest citronellol percentage in essential oil was observed in 2020, in the context of air temperatures close to normal and increased precipitation, at an average rate of $11.1 \pm 1.2 \%$ collection-wise. The range of variation was the highest as well, at 3.8-25.5\% collection-wise. In dry and hot weather conditions in 2018 and 2019, the mean values were $26.8 \%(1.9-17.8 \%)$ and $19.9 \%(3.4-17.5 \%)$ lower.

The geraniol content in essential oil was the highest of all the components correlated, and reached an average of $32.5 \pm 1.8,37.8 \pm 2.0$, and $33.0 \pm 2.0 \%$ collection-wise in 2018, 2019, and 2020, respectively. The geraniol content in essential oil was the highest in the context of scarcity of precipitation and moderately high temperatures in 2019. Differences in the variation range of the geraniol content in essential oils from the specimens analyzed during the study years were insignificant (13.2-44.4, 12.7-51.3, and 7.5-47.25\%, respectively).

In 2007-2008, Iranian researchers conducted a study of 49 Rosa damascena local varieties for the component composition, and based on the its findings, concluded that the citronellol and geraniol content in the rose essential oil increased in dry weather conditions [4]. However, temperature conditions should not be disregarded. Based on our observations, the best context for the accumulation of these components is increased precipitation along with moderate temperatures for citronellol. As for geraniol, it favored dry weather conditions along with moderate temperatures.

Extreme weather conditions in 2018 were highly unfavorable for nerol accumulation. Its average content in essential oil was 25.4 and 23.6\% lower than in 2019 and 2020, respectively. However, the variation range of the nerol content in essential oil year-wise did not differ significantly: $2.0-17.2 \% ; 1.8-17.2 \%$, and $1.6-20.5 \%$, respectively.

The stearoptenes content in essential oil of the specimens studied stayed within the standard requirements. The highest stearoptenes content in essential oil was observed in 2018 , at an average rate of $27.6 \pm 2.1 \%$ collection-wise. In the following two years (2019 and 2020 ), the stearoptenes content in essential oil was lower, at $20.2 \pm 1.8 \%$ and $21.5 \pm 2.6 \%$, respectively. The differences between the collection specimens in terms of the stearoptenes content in essential oil were quite significant. The variation range of the stearoptenes content in essential oil year-wise was 7.7-50.5\%, 6.1-39.5\%, and 5.3-63.4\%, respectively.

An analysis of the data obtained suggested that the high geraniol content and a low citronellol content, compared to the GOST ISO 9842-2917 standard requirements, in the essential oil of the study specimens, including the Bulgarian varieties cultivated in the piedmont of Crimea, was due to high temperature conditions and scarcity of precipitation. The study findings and analysis of literary sources suggest that cultivation of the RIACowned varieties in a different context (for example, in the Kazanlak Valley, Bulgaria) could also contribute to changes in the rose essential oil major components ratio and help bring it to the standard values of the Bulgarian rose oil [22].

Pearson's correlation coefficient was calculated for identifying the correlation of the major components content in the essential oil of the rose collection specimens studied. There was no correlation found between the citronellol and geraniol content $(r=-0.016)$, and a mid-level correlation found between the citronellol and nerol content $(r=0.27)$. A strong positive correlation $(\mathrm{r}=0.68)$ was identified between the nerol and geraniol content. Apart from essential oil, a valuable oil-bearing rose flower derivative is concrete isolated from the raw material by organic solvent extraction [11]. The average yield of concrete is $1 \mathrm{~kg} / 450 \mathrm{~kg}$ of fresh rose blossoms $(0.22-0.25 \%)$. Concrete is a wax-like substance, with a light-greenish or dark brown-colored, it solidifies at $44-45{ }^{\circ} \mathrm{C}$, has a characteristic odor of rose, and is partially soluble in alcohol. It contains waxes extractable with solvents but undistillable with water steam, a lipid complex, and coloring agents, as well as some organic acids, glycols, epoxy compounds, etc. The concrete composition is formularized as a pseudo ternary compound containing wax, substances soluble in ethanol, high molecular resins and essential oil (a water steam volatile component) chemically similar to distilled oil. The ethanol-soluble component separated from concrete and mixed with distilled essential oil is the so-called absolute essential oil (absolute) [11,16]. The yield of the absolute may reach $58-64 \%$ [23]. It was found that the oil-bearing rose absolute consists of beta phenylethyl 
alcohol, citronellol, geraniol, nerol, eugenol, methyleugenol, geranyl acetate, benzyl alcohol, nonadecane, nonadecene, and farnesol [24].

Concrete and absolute are highly valuable essential-oil-bearing rose derivatives. Presently, the overall production of concrete and absolute is far in excess of essential oil overall production. The key producers of rose concrete and absolute are France, Bulgaria and, to a lesser extent by far, Morocco. In these countries, concrete is produced from Rosa centifolia L., which has a very low yield of essential oil upon distillation (http:/ / viness.narod.ru/rosa_concret_absolu.htm, accessed on 19 December 2021).

In 2019-2020, the yield of concrete from the raw essential-oil-bearing rose collection specimens was analyzed. Due to the scarcity of raw material during the two years, only 30 specimens were analyzed for the yield of concrete. In 13 specimens, including the Raduga variety, the yield of concrete was $0.31-0.39 \%$. The availability of such specimens enabled the selection of varieties promising a high yield of concrete.

\section{Conclusions}

A comparative analysis of the essential-oil-bearing rose collection specimens identified their variability in terms of the mass fraction of essential oil $(\mathrm{Cv}=36.3 \%)$ and the major component contents in essential oil $(\mathrm{Cv}=22.1-45.9 \%)$, which is indicative of the source material's viability for breeding varieties with a high content of essential oil rich in the most valuable major components.

It was found that the most valuable major component contents in the rose essential oil (citronellol, geraniol, and nerol) are highly sensitive to weather conditions at the plant budding and flowering stage, as well as to drops in high temperature and extreme drought conditions. It was further found that in the context of the piedmont of Crimea, the component composition of essential oil from the Bulgarian rose varieties, including the Kazanlak rose, does not meet the standard requirements of GOST ISO 9842-2017.

Based on the findings of the essential-oil-bearing rose collection analysis, we identified seven specimens rich in essential oil contained in the raw plant material at $0.030-0.049 \%$, and 13 specimens with a high yield of concrete at $0.31-0.39 \%$, which are recommended for inclusion into the breeding process.

Author Contributions: Conceptualization, V.Z., N.N. and V.P.; methodology, N.N., V.P. and M.K.; software, S.S.; validation, N.N., V.P. and M.K.; research, V.Z., O.Z. and E.M.; resources, V.Z.; data curation, N.N.; writing—original draft preparation, N.N. and V.Z.; writing—review and editing, N.N. and V.P.; visualization, S.S.; supervision, E.M.; project administration, V.P.; funding acquisition, V.P. and M.K. All authors have read and agreed to the published version of the manuscript.

Funding: This research was carried out with the support of the Ministry of Education and Science of the Russian Federation under scientific projects No. EUG-2019-0007 /122012700385-3and No. FNZW-2022-0007/1021032425046-6.

Informed Consent Statement: Informed consent was obtained from all subjects involved in the study.

Data Availability Statement: In this study, the samples of oil roses from the collections of essential oil, spicy aromatic, and medicinal plants were used (No. 507515 (http: / / www.ckp--rf.ru (accessed on 19 December 2021))).

Conflicts of Interest: The authors declare no conflict of interest.

\section{References}

1. Rabotyagov, V.D.; Paliy, A.E.; Kurdyukova, O.N. Essential Oils of Aromatic Plants: Monograph; IT "ARIAL": Simferopol, Russia, 2017; pp. 29-30.

2. Voytkevich, S.A. Essential Oils for Perfumery and Aromatherapy; Food Industry: Moscow, Russia, 1999; 284p.

3. Kovatcheva, N.; Zheljazkov, V.D.; Astatkie, T. Productivity, Oil Content, Composition and Bioactivity of Oil-Bearing Rose Accessions. HortScience 2011, 46, 710-714. [CrossRef]

4. Yousefi, B.; Jaimand, K. Chemical Variation in the Essential Oil of Iranian Rosa damascena Landraces under Semi-Arid and Cool Conditions. Int. J. Hortic. Sci. Technol. 2018, 5, 81-92. 
5. Tambe, E.; Gotmare, S.R. Study of Variation and Identification of Chemical Composition in Rosa Species Oil Collected from Different Countries. IOSR-JAC 2016, 9, 11-18.

6. Pashtetsky, V.S.; Nevkrytaya, N.V. Use of essential oils in medicine, aromatherapy, veterinary and crop production (review). Taurida Her. Agrar. Sci. 2018, 1, 18-40.

7. Kumari, S.; Choudhury, A.G. Medicinal Uses of Rose. Vigyan Varta 2021, 2, 49-51.

8. Sahakyan, N.Z.; Petrosyan, M.T.; Trchounian, A.H. Some peculiarities of essential oil of Damask rose growing in high altitude Armenian landscapes. Chem. Biol. 2020, 54, 68-74. [CrossRef]

9. The State Register of Selection Achievements Authorized for Use (National List). In Plant Varieties (Official Publication); FGBNU "Rosinformagrotekh": Moscow, Russia, 2021; Volume 1,719p. Available online: https://gossortrf.ru/ (accessed on 22 April 2021).

10. Karpacheva, A.N. Biochemical Methods of Essential-Oil Plants and Essential Oils Analysis; URIEOC: Simferopol, Russia, 1972; 107p.

11. Pashtetskiy, V.S.; Timasheva, L.A.; Pekhova, O.A.; Danilova, I.L.; Serebryakova, O.A. Essential Oils and Their Quality; IT "ARIAL": Simferopol, Russia, 2021; pp. 9-14.

12. GOST 34213-2017 Floral and Herbal Essential-Oil-Bearing Plant Raw Material. Sampling Techniques and Water, Foreign Matter and Essential Oil Content Determination Methods. Available online: https:/ / docs.cntd.ru/document/1200157884 (accessed on 21 December 2021).

13. Leontyev, V.N.; Shutova, A.G.; Kovalenko, N.A.; Supichenko, G.N.; Spiridovich, E.V. Essential oils identification by gas chromatography. Publ. Belarus State Univ. 2006, 1, 261-267.

14. Zenkevich, I.G.; Pimenov, A.I.; Pozharitskaya, O.N.; Shikov, A.N.; Makarov, V.G. Chromatographic profiles comparison as a method for identifying medicinal plant raw material components in complex preparations. Plant Resour. 2003, 39, 143-152.

15. Dospekhov, B.A. Plot Trials Procedure (Including the Basics of the Research Findings Statistical Processing); Book Upon Request: Moscow, Russia, 2012; 352p.

16. Nazarenko, L.G.; Korshunov, V.A.; Kochetkov, E.S. Essential-Oil Rose Growing and Breeding; Tavriya: Simferopol, Ukraine, 2006; 216p.

17. GOST ISO 9842-2017 Essential Oil of Rose (Rosa x Damascene Miller). Specifications. Available online: https: / / docs.cntd.ru/ document/1200147041 (accessed on 16 June 2021).

18. Saeed, R.; Gul, S.; Khan, M.A.; Kamboh, M.A.; Khan, M.I.; Sherazi, S.T.H. GC-MS Evaluation of Essential Oil Constituents from Rosa Damascena Wild Rose: Effect of Season and Climatic Conditions. Pak. J. Anal. Environ. Chem. 2017, 18, 155-162. [CrossRef]

19. Nevkrytaya, N.V.; Pashtetskiy, V.S.; Novikov, I.A.; Korotkikh, I.N.; Tkhaganov, R.R. Variability of component composition of Melissa officinalis L. essential oil depending on the climatic conditions of the region of cultivation. Chem. Plant Raw Mater. 2020, 1, 257-263. [CrossRef]

20. Toluei, Z.; Hosseini Tafreshi, S.A.; Arefi Torkabadi, M. Comparative Chemical Composition Analysis of Essential Oils in Different Populations of Damask Rose from Iran. J. Agric. Sci. Tech. 2019, 21, 423-437.

21. Moein, M.; Ghasemi, Y.; Karami, F.; Tavallali, H. Composition of the essential oil of Rosa damascenea Mill. from South of Iran. Iran. J. Pharm. Sci. 2010, 6, 59-62.

22. Atanasova, T.; Kakalova, M.; Stefanof, L.; Petkova, M.; Stoyanova, A.; Damyanova, S.; Desyk, M. Chemical composition of essential oil from Rosa Damascena mill., growing in new region of Bulgaria. Ukr. Food J. 2016, 5, 492-498. [CrossRef]

23. Aydinli, M.; Tutaş, M. Production of rose absolute from rose concrete. Flavour Fragr. J. 2003, 18, 26-31. [CrossRef]

24. Ayc1, F.; Aydınlı, M.; Bozdemir, Ö.A.; Tutaş, M. Gas chromatographic investigation of rose concrete, absolute and solid residue. Flavour Fragr. J. 2005, 20, 481-486. [CrossRef] 